Int. J. Dev. Biol. 57: 351-356 (2013)

doi: $10.1387 / \mathrm{ijdb} .120217 \mathrm{gr}$

\title{
Sexual dimorphism in estrogen-induced synaptogenesis in the adult hippocampus
}

\author{
NICOLA BRANDT, RICARDO VIERK and GABRIELE M. RUNE* \\ Institute of Neuroanatomy, University Medical Center Hamburg-Eppendorf, Hamburg, Germany
}

\begin{abstract}
It has long been known that estradiol influences synaptic plasticity in the female hippocampus. The density of dendritic spines varies during the estrous cycle and correlates positively with varying levels of estradiol in serum. In accordance, ovariectomy results in a loss of spines that can be rescued by estradiol treatment in animals, suggesting that estradiol originating from the ovaries induces spine formation in the hippocampus. More recent studies point to a role of hippocampusderived estradiol in synaptogenesis in the female hippocampus, rather than of estradiol of ovarian origin. In our studies, we have shown that inhibition of hippocampal estrogen synthesis results in spine synapse loss in female animals and, more importantly, also in ovariectomized animals. Surprisingly, inhibition of local estradiol synthesis had no effect on synapse formation in males, in spite of a similar capacity to synthesize estradiol in male and female hippocampal neurons. In females, neuro-sexual steroid production is promoted by hypothalamic, cyclic $\mathrm{GnRH}$ release and likely underlies the estrus cyclicity of spine synapse density in the hippocampus. As a result, peripheral serum concentrations of estradiol determine the amount of estradiol synthesis in the hippocampus. This paradigm may also be true in males. In support of this hypothesis, we found that the content of estradiol in hippocampal tissue is higher in female compared to that in male animals, with low levels of estradiol in serum and tonic and acyclical GnRH release. In summary, our data point to important sex-specific differences in sexual steroid-induced synaptogenesis.
\end{abstract}

KEY WORDS: aromatase, estrogen, synaptogenesis, hippocampus, sexual dimorphism

\section{Introduction}

In the early nineties, it became evident that hormones, namely estrogens, influence synaptic plasticity. At that time, McEwen and co-workers discovered that ovariectomy results in loss of postsynaptic dendritic spines on hippocampal neurons of the CA1 region (Gould et al., 1990). As systemic injections of estradiol into these animals restored dendritic spine reduction, it appeared plausible to believe that estradiol originating from the ovaries influences spine density in the hippocampus. The subsequent finding, showing that spine density varies with the estrous cycle, was consistent with this hypothesis, i.e. that ovary-derived estradiol in serum is capable of controlling spine density in the hippocampus (Woolley et al., 1990). When estradiol concentrations are highest in serum at proestrus, shortly before ovulation, spine density has reached its maximum and the density of spines decreases thereafter, along with decreasing levels of estradiol in serum. Altogether, these data underline the high plasticity of synapses, or at least of postsynaptic spines, in the hippocampus and show estrogen-induced synaptogenesis to be a prominent example of adult synaptogenesis.

Despite the great number of studies that followed the initial studies on estrogen-induced synaptogenesis and related phenomena (for review see Spencer et al., 2008), many questions, in particular many basic endocrinological questions, remained unanswered or were ignored. Two points may be particularly emphasized: serum concentrations in female rats are around $0.1 \mathrm{nM}$ and are even lower in males. An increase in spine density due to estradiol, however, is generally accepted to take place in response to $1 \mathrm{nM}$ estradiol in vitro in males as well as in females (Kramar et al., 2009). To detect estrogenic effects in females, ovariectomized animals were commonly used for systemic treatment, which does not allow for the discrimination of a direct estrogenic effect from an indirect effect, since the removal of ovaries includes many more factors than merely estradiol. Another important issue is the relevance of systemic estrogenic effects in males, which were frequently

Abbreviations used in this paper: EGFP, enhanced green fluorescent protein.

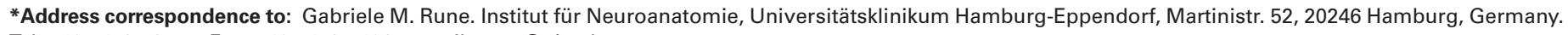
Tel: +49-7410-53575. Fax: +49-7410-5496. e-mail: rune@uke.de
} 
taken for the experiments to avoid cyclicity. Not only were the doses applied tremendously higher than the physiological serum concentrations, but also the question as to how the rather high doses of estradiol could interfere with other metabolic processes, such as the synthesis of other sexual steroids in the animals, was never considered.

\section{Hippocampal neurons synthesize estradiol independent of gender}

Naftolin and co-workers (Naftolin et al., 1971) were the first to describe aromatase expression in the diencephalon. Aromatase is the final enzyme of estradiol synthesis and catalyzes the conversion of testosterone to estradiol. It has meanwhile been established that the brain is equipped with all the enzymes of estrogen synthesis, including aromatase (Shibuya et al., 2003; Do Rego et al., 2009; Pelletier, 2010). The actual synthesis and secretion of estradiol from hippocampal neurons, however, was not shown until many years later (Prange-Kiel et al., 2003). We showed that adult cultured hippocampal neurons are capable of synthesizing estradiol de novo, which was confirmed by Hojo and co-workers (Hojo et al., 2004). Prange-Kiel and co-workers cultured isolated adult neurons under serum- and steroid-free conditions, which allowed them to postulate that the neurons synthesize estradiol de novo from cholesterol. To further substantiate the de novo synthesis of estradiol in hippocampal neurons, we performed a knockdown of steroidogenic acute regulatory protein (StAR). StAR transports cholesterol through the mitochondrial membranes, since the first enzyme of estrogen synthesis, the side chain cleavage enzyme $\left(\mathrm{SCC} \mathrm{P}_{450}\right)$, is located at the inner mitochondrial membrane, where steroidogenesis commences (Jefcoate, 2002; Rone et al., 2009). An earlier study by our group had demonstrated the expression of StAR together with aromatase in the hippocampus (Wehrenberg et al., 2001). After transfection of hippocampal neurons with siRNA against StAR, estradiol synthesis in the neurons was clearly reduced, further indicating that estradiol is synthesized de novo from cholesterol in hippocampal neurons (Fester et al., 2006; Fester et al., 2009a).

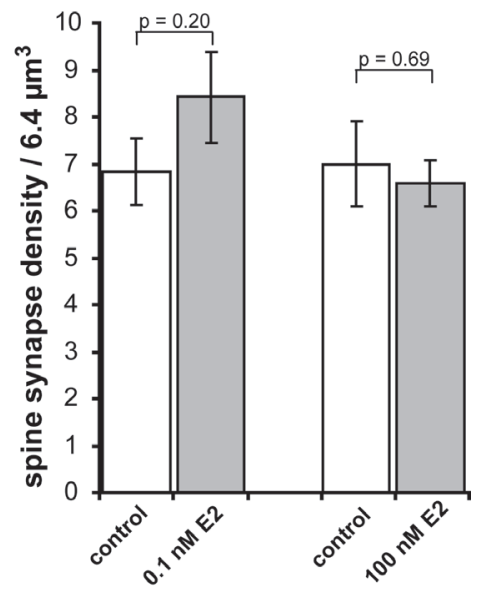

female

Fig. 1. Spine synapse density in female hippocampal slice cultures after estradiol treatment at a dose of $0.1 \mathrm{nM}$ (physiological female serum concentration) and $100 \mathrm{nM}$ estradiol for 7 days. No significant differences were detected between treated and non-treated cultures. (mean \pm SEM, $n=5 ;{ }^{*}$ Student $t$-test, $p \leq 0.05$ ).

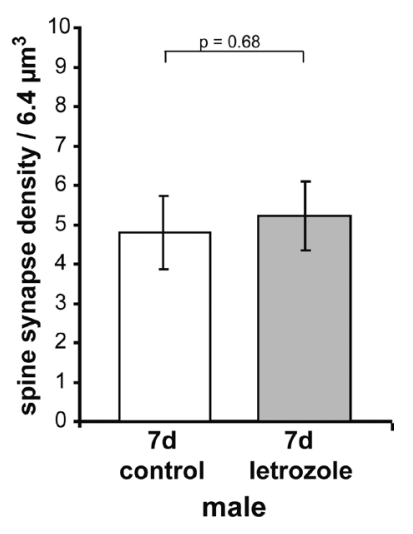

Fig. 2. Spine synapse density in male hippocampal slice cultures in response to inhibition of aromatase at a dose of $100 \mathrm{nM}$ letrozole for 7 days. No significant differences were detected between treated and non-treated cultures. (mean $\pm S E M, n=5 ;{ }^{*}$ Student $t$-test, $\left.p \leq 0.05\right)$.

With respect to our basic question regarding the role of local estradiol synthesis in estrogen-induced synaptic plasticity, we manipulated the amount of neuronal estradiol secretion by upregulation and downregulation of aromatase as the last step of estrogen synthesis. For the upregulation we added substrates of estrogen synthesis, such as cholesterol and testosterone, to the cultures and for the downregulation we used aromatase inhibitors, which are commercially available and commonly used in the therapy of postmenopausal women who suffer from breast cancer.

Cholesterol, as well as testosterone, the direct substrate of aromatase, stimulate estradiol synthesis dramatically, cholesterol to a higher degree than testosterone (Fester et al., 2009a). The aromatase inhibitor letrozole, which we used for our experiments, is a non-steroidogenic, reversible inhibitor that reduces the synthesis and release of estradiol from newborn hippocampal slice cultures and dissociated hippocampal neurons dose-dependently, by a maximum of $40 \%$ (for review see Fester et al., 2011). Potential toxic effects could be ruled out up to a dose of $100 \mathrm{nM}$ and the reversibility of the effects was seen within 32 hours (Fester et al., 2006; Prange-Kiel et al., 2006).

In vitro, the capacity of estradiol synthesis was independent of gender. When we compared the amount of estradiol synthesis in dissociated cultures that originated from male animals with cultures that originated from female animals, no difference was found in the amount of estradiol in the supernatant, as evidenced by radioimmunoassay (Fester et al., 2012).

\section{Local estradiol synthesis controls spine synapse density in the hippocampus of female but not of male animals}

In our first experiments on the role of local estradiol synthesis on synaptogenesis, we used hippocampal cultures to exclude any potential estrogenic influence from peripheral sources. In hippocampal slice cultures, the density of spine synapses was stereologically determined in electron micrographs. For determination of spine density we used EGFP-transfected, serum- and steroid-free hippocampal dissociated neurons.

In previous experiments, we had not found estradiol treatment to have any effect on spine synapse density in hippocampal slice cultures; neither with physiological serum concentrations of estradiol nor with high doses of $100 \mathrm{nM}$ estradiol for 7 days, was an 
increase in spine synapse density detected (Fig. 1). This holds true for cultures originating from female, as well as for those originating from male animals (Kretz et al. 2004).

In contrast, the inhibition of aromatase by letrozole and the consequent lowering in estradiol synthesis in cultures that were prepared from female animals, resulted in a significant and clear reduction in the number of spine synapses in the CA1 hippocampal region (Kretz et al., 2004). This effect was restored by simultaneous application of estradiol and letrozole, the aromatase inhibitor we used in our experiments (Zhou et al., 2007). No effect was seen after letrozole treatment in cultures that originated from male animals (Fig. 2). Spine synapse loss in "female" hippocampal cultures is likely to result from the dramatic impairment of long term potentiation in response to letrozole treatment, since LTP impairment precedes spine synapse loss and LTP was shown to induce spine formation (Yuste and Bonhoeffer, 2001, 2004). No such effect on LTP in response to inhibition of aromatase was seen in males (Vierk et al., 2012)

In order to be sure that the effects we found after inhibition of aromatase were not due to elevated levels of precursors of estrogen synthesis, we had previously tested in mixed hippocampal slice cultures of male and female animals the effects of cholesterol and testosterone. Spine synapse density and estradiol levels, as described above, were both significantly increased (Fester et al., 2009a). However, the effects after treatment with cholesterol and testosterone respectively were abolished in the presence of letrozole, pointing to the specificity of estradiol synthesis and showing that cholesterol and testosterone are ineffective unless they are metabolized to estradiol.

Two types of spines are present in the hippocampus and in the neocortex: thin spines, which are considered to be more dynamic and transient in character, and mushroom spines, which are believed to be mature, stable spines that can persist for months (Holtmaat et al., 2005; Zuo et al., 2005). Mushroom spines have larger postsynaptic densities (Harris et al., 1992) that anchor more AMPA receptors and make these synapses functionally stronger (Matsuzaki et al., 2001; Ganeshina et al., 2004; Ashby et al., 2006; Majewska et al., 2006). Compared to thin spines, mushroom spines often contain polyribosomes for local protein synthesis (Haber and
Murai, 2006; Witcher et al., 2007). Accordingly, mushroom spines are proposed to be memory spines (Tada and Sheng, 2006; Bourne and Harris, 2007; Kasai et al., 2010). By using EGFP-transfected dissociated hippocampal neurons, we counted the number of spines and determined the phenotype of spines (thin versus mushroom spine) on "male" as well as on "female" neurons. In the controls, we found that male and female neurons differ in the composition of the spine phenotype. "Female" neurons exhibited more mushroom spines than "male" neurons, while it was vice versa with respect to thin spines: the proportion of thin spines was larger in neurons from males than in neurons from females (Vierk et al., 2012). Treatment of these cultures with letrozole resulted in considerable loss of spines on female neurons but not on male neurons. Total spine number was reduced by less than $9 \%$ in male neurons, compared to roughly $40 \%$ in female neurons (Fig. 3). Most importantly, spine loss on female neurons in response to letrozole consisted predominantly of mature, mushroom spines and to a lesser degree of thin spines. In contrast, mature mushroom spines were unaffected after aromatase inhibition on male neurons and spine loss, if any, included only thin spines (Vierk et al., 2012). Aside from the clear-cut differences between genders, the results show that in females, aromatase inhibition preferentially effects mushroom spines, which are considered to represent memory spines. The reduction in mature spines in females and in female hippocampal slice cultures after letrozole treatment is in agreement with the findings of Matsuzaki et al. (Matsuzaki et al., 2004) showing that LTP, which is strongly impaired after letrozole treatment and precedes spine synapse loss, causes spines to develop a round configuration. As a conclusion, spine synapse loss in females appears to preferentially affect synapses with large spines, rather than thin spines. In contrast, the number of spine synapses and the number of mature spines were unchanged in males and were very much consistent, with no change in LTP. Consistent with the in vitro data on spine density on male single neurons and spine synapse density in male hippocampal slice cultures in response to letrozole, systemic treatment of male adult animals with the aromatase inhibitor had no effect, even after 4 weeks of treatment with letrozole (Zhou et al., 2010; Fester et al., 2012).

Finally, when we treated adult female animals daily with letro-
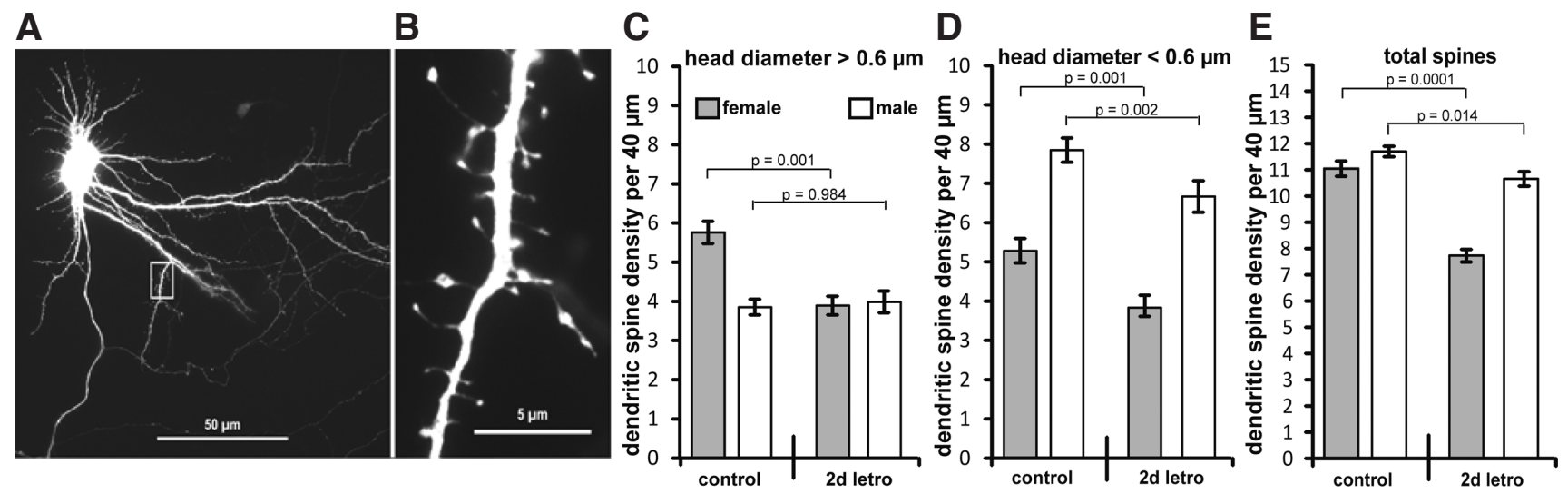

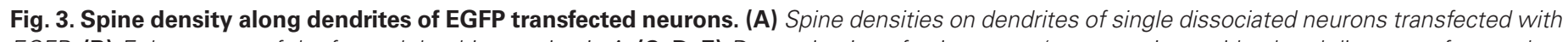

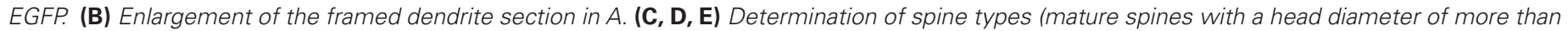

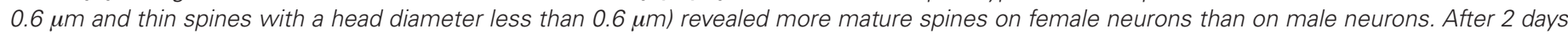

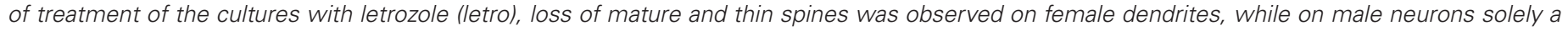
reduction in thin spines was seen. (means \pm SEM; $n=3$ independent cultures; a total of 30 neurons in each group were used). 
zole for 7 days and 4 weeks we found, as expected, a reduction in spine synapse number, not only in intact females but also in ovariectomized animals (Zhou et al., 2010). These data nicely confirm our in vitro results and most importantly, strongly suggest and support our hypothesis that estradiol of ovarian origin does not play the primary role. Altogether, our findings show that local estradiol controls spine synapse density in the hippocampus of females, rather than estradiol from peripheral sources.

\section{How can the estrus cyclicity of synaptogenesis in fe- males be explained?}

In spite of spine synapse loss in ovariectomized mice in response to letrozole and the ineffectiveness of treatment of our hippocampal slice cultures with estradiol, which both argue for a primary role of local estradiol synthesis in estrogen-induced synaptic plasticity, the estrus cyclicity of spine density in the female hippocampus appeared to be discrepant with our hypothesis and needed to be addressed.

Serum levels of estradiol, which preferentially correspond to the synthesis of estradiol in ovarian granulosa cells, control the hypothalamo-pituitary-gonadal axis via a feed-back mechanism. Classically, estradiol serum levels control the release of $\mathrm{GnRH}$ from the hypothalamus, which in turn stimulates the pituitary to secrete $\mathrm{FSH} / \mathrm{LH}$, which enhances the synthesis of estradiol in ovarian granulosa cells. It was, however, also shown that $\mathrm{GnRH}$ is able to directly stimulate granulosa cells with regard to their ability to synthesize estradiol. Much to our surprise, $\mathrm{GnRH}$ receptors are abundant in the hippocampus and mRNA is at its highest levels in this brain region, compared to the cortex and the hypothalamus (Prange-Kiel et al., 2008). Based upon the idea that GnRH could also stimulate estradiol synthesis in the hippocampus, similar to its effect on granulosa cells, we treated our hippocampal cultures with $\mathrm{GnRH}$. GnRH stimulated both estradiol synthesis in hippocampal neurons and spine synapse density in an identical dose-dependent manner. The effect on synapse density was abolished when we applied $\mathrm{GnRH}$ together with letrozole, the aromatase inhibitor, to the cultures, showing that $\mathrm{GnRH}$ regulates spine synapse density

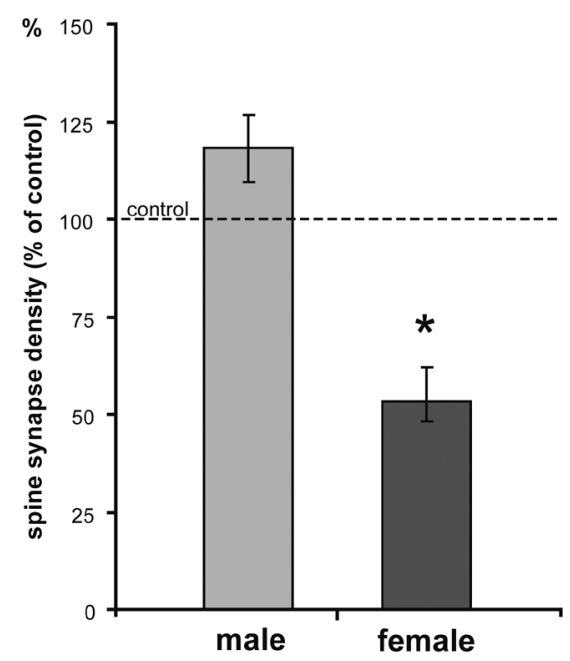

Fig. 4. Changes in spine synapse density in male and female hippocampi after systemic treatment with letrozole for $\mathbf{4}$ weeks. Letrozole significantly reduced synapse density in females but not in males (mean $\pm S E M, n=5 ;{ }^{*} p \leq 0.05$ ). via regulation of the estradiol synthesis in hippocampal neurons. These in vitro findings strongly suggest that the release of $\mathrm{GnRH}$ upon varying estradiol levels during the estrus cycle synchronizes the ovarian and the "hippocampal" cycle. Increasing levels of estradiol in serum during the follicular phase give rise to an increasing release of $\mathrm{GnRH}$ from the hypothalamus, which not only stimulates estradiol synthesis in the ovaries via $\mathrm{LH}$, but also directly stimulates estradiol synthesis in the hippocampus. Finally, injections of $\mathrm{GnRH}$ into the hippocampus of female animals also had promoting effects on synaptogenesis (unpublished data). Although we do not know yet how $\mathrm{GnRH}$ from the hypothalamus reaches the hippocampus, as direct neuronal connections do not exist, $\mathrm{GnRH}$ is found in cerebrospinal fluid (Skinner and Caraty, 2002) and thus $\mathrm{GnRH}$ could have access to the hippocampus via the median eminence, organum vasculosum of the lamina terminalis, and retrograde blood flow (Lehman et al., 1986). All have been suggested as a potential source of $\mathrm{GnRH}$ in the cerebrospinal fluid. In addition, sexual behaviour was shown to be influenced by injection of GnRH into the ventricles (Pfaff et al., 1994). Our findings were confirmed by Meethal et al. (2009), showing that peripheral sex steroids modulate $\mathrm{GnRH}$-receptor signalling and gonadotropin-induced StAR-mediated uptake of mitochondrial cholesterol for neurosteroid synthesis, such as estrogen. These data support the dependency of neurosteroid synthesis on the hypthalamo-hypophyseal-gonadal axis.

This dependency could also help to understand why the content of estradiol in hippocampal tissue as measured by mass spectrometry differs between males and proestrus females (Fester et al., 2012), although the capacity of estradiol synthesis in dissociated single hippocampal neurons does not differ between males and females. Robust functional sex differences have been identified in hypothalamic circuitry regulating reproductive function. Increasing levels of estradiol synthesized by granulosa cells in ovaries and released into the blood stream trigger the release of $\mathrm{GnRH}$ from neurons scattered throughout the hypothalamus, which in turn induce the mid-cycle surge in LH, which is essential for ovulation. In contrast, in male rats the pattern of $\mathrm{LH}$ release upon $\mathrm{GnRH}$ stimulation is tonic and acyclic leading to a steady state of testosterone, which always exerts a negative feed back on $\mathrm{GnRH}$ release (for review see Gillies and McArthur, 2010). The lack of cyclic variations of $\mathrm{GnRH} / \mathrm{LH}$ in males, together with the findings by Meethal et al. (2009) showing that periperhal concentrations of estradiol influence StAR, could account for the difference in the content of estradiol in hippocampal tissue between males and females.

\section{Pre- and postsynaptic marker proteins are regulated by local estradiol synthesis, independent of the regulation of synapse maintenance}

Parallel to our studies on estrogen-controlled spine and spine synapse density in the hippocampus we studied pre- and postsynaptic marker proteins, which are frequently taken to be indicative of synapse formation. We used synaptophysin as a presynaptic marker and spinophilin as a postsynaptic marker. Synaptophysin is a constituent of the transmitter vesicle membrane and spinophilin is an actin-associated protein which is enriched in spines (Feng etal., 2000). Both proteins turned out to be highly responsive to estradiol (Murphy and Segal, 1996; Brake etal., 2001; Rune etal., 2002; Hao et al., 2003; Kretz et al., 2004; Fester et al., 2009b). In contrast to our findings on synapse formation, application of estradiol to the 
cultures upregulated the protein and, consistent with our findings on synapse formation, they were downregulated in response to letrozole, thus after inhibition of aromatase in the hippocampal cultures. As far as the upregulation after estradiol is concerned, it has to be mentioned that the upregulation was seen at $100 \mathrm{nM}$ of $17 ß$-estradiol but not at physiological serum concentrations of estradiol, neither in cultures originating from males nor in cultures originating from females (Kretz et al., 2004). After knockdown of StAR, thus after inhibition of estrogen synthesis from its beginning, the proteins were also downregulated. This downregulation was rescued when we applied estradiol to the cultures that were transfected with siRNA against aromatase. It is noteworthy in this context that cholesterol and testosterone failed to rescue the downregulation of the proteins after knockdown of StAR, showing the specificity of estrogenic effects on the expression of synaptic proteins (Fester et al., 2009b).

By using spinophilin and synaptophysin expression and their responsiveness to estradiol we were best able to demonstrate the auto/paracrine character of estrogen-regulated synaptogenesis, since steroidogenic proteins, such as StAR and aromatase, are expressed in a region-specific manner and the proteins were downregulated in a similar region-specific manner (Prange-Kiel et al., 2006). Both the region-specific expression of steroidogenic enzymes and the identical region-specific downregulation of synaptic proteins in response to a defined dose of letrozole strongly suggest that estradiol, synthesized and released in defined regions within the hippocampus, also exerts its influence in exactly these areas.

In intact female animals, synaptophysin and spinophilin were also downregulated after daily injections of letrozole for 7 days and 4 weeks. It is notable that the proteins were dramatically upregulated in ovariectomized animals after 4 weeks of letrozole treatment, in spite of persistent spine synapse loss. This effect was not seen after 7 days of treatment. Obviously, protein expression only transiently correlates with spine and spine synapse formation. This finding led us to speculate that long-lasting estradiol depletion may induce a counter regulation in order to strengthen synaptic functionality.

In a more general sense, it appears questionable from these findings to take the expression of synaptic proteins to be indicative of synapse formation, since in the case of estrogen-induced structural synaptic plasticity, synaptic proteins are regulated independently from spinogenesis and synaptogenesis respectively.

\section{Conclusion}

Our findings over the last years strongly suggest that hippocampus-derived estradiol regulates synaptogenesis in the hippocampus rather than estradiol originating from peripheral sources such as the ovaries. Regulation of synapse density by local estradiol synthesis, is however, only valid in female, but not in male animals. This clear-cut sex-specific difference points to the necessity for further studies on the potential influence of sexual steroids on synaptogenesis in male animals.

\section{Acknowlegdements}

The study was supported by the DFG.

\section{References}

ASHBY MC, MAIER SR, NISHIMUNE A, HENLEY JM (2006) Lateral diffusion drives constitutive exchange of AMPA receptors at dendritic spines and is regulated by spine morphology. J Neurosci 26: 7046-7055.

BOURNE J, HARRIS KM (2007) Do thin spines learn to be mushroom spines that remember? Curr Opin Neurobiol 17: 381-386.

BRAKE WG, ALVES SE, DUNLOP JC, LEE SJ, BULLOCH K, ALLEN PB, GREENGARD P, MCEWEN BS (2001) Novel target sites for estrogen action in the dorsa hippocampus: an examination of synaptic proteins. Endocrinology 142: 1284-1289.

DO REGO JL, SEONG JY, BUREL D, LUU-THE V, LARHAMMAR D, TSUTSUI K, PELLETIER G, TONON MC, VAUDRY H (2009) Steroid biosynthesis within the frog brain: a model of neuroendocrine regulation. Ann N Y Acad Sci 1163: 83-92.

FENG G, MELLOR RH, BERNSTEIN M, KELLER-PECK C, NGUYEN QT, WALLACE M, NERBONNE JM, LICHTMAN JW, SANES JR (2000) Imaging neuronal subsets in transgenic mice expressing multiple spectral variants of GFP. Neuron 28: 41-51.

FESTER L, PRANGE-KIEL J, JARRY H, RUNE GM (2011) Estrogen synthesis in the hippocampus. Cell Tissue Res 345: 285-294.

FESTER L, RIBEIRO-GOUVEIA V, PRANGE-KIELJ, VON SCHASSEN C, BOTTNER M, JARRY H, RUNE GM (2006) Proliferation and apoptosis of hippocampal granule cells require local oestrogen synthesis. J Neurochem 97: 1136-1144.

FESTER L, ZHOU L, BUTOW A, HUBER C, VON LOSSOW R, PRANGE-KIEL J, JARRY H, RUNE GM (2009a) Cholesterol-promoted synaptogenesis requires the conversion of cholesterol to estradiol in the hippocampus. Hippocampus 19: $692-705$

FESTER L, ZHOU L, VOETS C, OSSIG C, DISTELDORF E, BLAUTE F, PRANGEKIEL J, DUDZINSKI D, JARRY H, RUNE GM (2009b) The opposing roles of estradiol on synaptic protein expression in hippocampal cultures. Psychoneuroendocrinology 34: S123-S129.

FESTERL, PRANGE-KIEL, J. ZHOU, L., VONBLITTERSDORF, B., BÖHM, J., JARRY, H., SCHUMACHER, M., RUNE, GM. (2012) Estrogen-regulated synaptogenesis: sexual dimorphism in vivo but not in vitro. J Steroid Biochem Mol Biol 131: 24-29

GANESHINAO, BERRYRW, PETRALIARS, NICHOLSONDA, GEINISMANY (2004) Differences in the expression of AMPA and NMDA receptors between axospinous perforated and nonperforated synapses are related to the configuration and size of postsynaptic densities. J Comp Neurol 468: 86-95.

GILLIES GE, MCARTHUR S (2010) Estrgen actions in the brain and the basis for differential action in me and women: a case for sex-specific medicines. Pharmacol Rev 62: 155-198.

GOULD E, WOOLLEY CS, FRANKFURT M, MCEWEN BS (1990) Gonadal steroids regulate dendritic spine density in hippocampal pyramidal cells in adulthood. $J$ Neurosci 10: 1286-1291.

HABER M, MURAI KK (2006) Reshaping neuron-glial communication at hippocampal synapses. Neuron Glia Biol 2: 59-66.

HAO J, JANSSEN WG, TANG Y, ROBERTS JA, MCKAY H, LASLEY B, ALLEN PB GREENGARD P, RAPP PR, KORDOWER JH, HOF PR, MORRISON JH (2003) Estrogen increases the number of spinophilin-immunoreactive spines in the hippocampus of young and aged female rhesus monkeys. J Comp Neurol465: 540-550.

HARRIS KM, JENSEN FE, TSAO B (1992) Three-dimensional structure of dendritic spines and synapses in rat hippocampus (CA1) at postnatal day 15 and adult ages: implications for the maturation of synaptic physiology and long-term potentiation. $\checkmark$ Neurosci 12: 2685-2705.

HOJOY, HATTORI T, ENAMI T, FURUKAWAA, SUZUKI K, ISHII HT, MUKAI H, MORRISON JH, JANSSEN WGM, KOMINAMI S, HARADA N, KIMOTO T, KAWATO $S$ (2004) Adult male rat hippocampus synthesizes estradiol from pregnenolone by cytochromes P45017 alpha and P450 aromatase localized in neurons. Proc. Natl. Acad. Sci. USA 101: 865-870.

HOLTMAAT AJ, TRACHTENBERG JT, WILBRECHT L, SHEPHERD GM, ZHANG X, KNOTT GW, SVOBODA K (2005) Transient and persistent dendritic spines in the neocortex in vivo. Neuron 45: 279-291.

JEFCOATE C (2002) High-flux mitochondrial cholesterol trafficking, a specialized function of the adrenal cortex. J Clin Invest 110: 881-890.

KASAI H, FUKUDA M, WATANABE S, HAYASHI-TAKAGI A, NOGUCHI J (2010) Structural dynamics of dendritic spines in memory and cognition. Trends $\mathrm{Neu}$ rosci 33: 121-129.

KRAMAR EA, CHEN LY, BRANDON NJ, REX CS, LIU F, GALL CM, LYNCH G (2009) Cytoskeletal changes underlie estrogen's acute effects on synaptic transmission and plasticity. J Neurosci 29: 12982-12993.

KRETZ O, FESTER L, WEHRENBERG U, ZHOU L, BRAUCKMANN S, ZHAO S PRANGE-KIEL J, NAUMANN T, JARRY H, FROTSCHER M, RUNE GM (2004) 
Hippocampal synapses depend on hippocampal estrogen synthesis. J Neurosci 24: 5913-5921.

LEHMAN MN, ROBINSON JE, KARSCH FJ, SILVERMAN AJ (1986) Immunocytochemical localization of luteinizing hormone-releasing hormone (LHRH) pathways in the sheep brain during anestrus and the mid-luteal phase of the estrous cycle. J Comp Neurol 244: 19-35.

MAJEWSKA AK, NEWTON JR, SUR M (2006) Remodeling of synaptic structure in sensory cortical areas in vivo. J Neurosci 26: 3021-3029.

MATSUZAKI M, ELLIS-DAVIES GC, NEMOTO T, MIYASHITA Y, IINO M, KASAI H (2001) Dendritic spine geometry is critical for AMPA receptor expression in hippocampal CA1 pyramidal neurons. Nat Neurosci 4: 1086-1092.

MATSUZAKIS, CANISM, VAURS-BARRIERE C, POULY JL, BOESPFLUG-TANGUY O,PENAULT-LLORCAF, DECHELOTTEP, DASTUGUEB, OKAMURAK, MAGE G (2004) DNA microarray analysis of gene expression profiles in deep endometriosis using laser capture microdissection. Mol Hum Reprod 10: 719-728.

MEETHAL SV, LIU TL, CHAN HW, GINSBURG E, WILSON AS, GRAY DN, BOWEN RL, VONDERHAAR BK, ATWOOD CS (2009) Indentification of a regulatory loop for the synthesis of neurosteroids: a steroidogenic acute regulatory proteindependent mechanism involving hypothalamic-pituitary-gonadal axis receptors. $J$ Neurochem 110: 1014-1027.

MURPHY DD, SEGAL M (1996) Regulation of dendritic spine density in cultured rat hippocampal neurons by steroid hormones. J Neurosci 16: 4059-4068.

NAFTOLIN F, RYAN KJ, PETRO Z (1971) Aromatization of androstenedione by the diencephalon. J Clin Endocrinol Metab 33: 368-370.

PELLETIER G (2010) Steroidogenic enzymes in the brain: morphological aspects. Prog Brain Res 181: 193-207.

PFAFF DW, SCHWANZEL-FUKUDAM, PARHAR IS, LAUBERAH, MCCARTHY LM, KOW LM (1994) GnRH neurons and other cellular and molecular mechanisms for simple mammalian reproductive behaviors. Recent Prog Horm Res 49: 1-25.

PRANGE-KIELJ, WEHRENBERG U, JARRYH, RUNEGM (2003) Para/autocrine regulation of estrogen receptors in hippocampal neurons. Hippocampus 13: 226-234.

PRANGE-KIEL J, FESTER L, ZHOU L, LAUKE H, CARRETERO J, RUNE GM (2006) Inhibition of hippocampal estrogen synthesis causes region-specific downregulation of synaptic protein expression in hippocampal neurons. Hippocampus 16:464-471.

PRANGE-KIEL J, JARRY H, SCHOEN M, KOHLMANN P, LOHSE C, ZHOU L, RUNE GM (2008) Gonadotropin-releasing hormone regulates spine density via its regulatory role in hippocampal estrogen synthesis. J Cell Biol 180: 417-426.

RONE MB, FAN J, PAPADOPOULOS V (2009) Cholesterol transport in steroid biosynthesis: role of protein-protein interactions and implications in disease states. Biochim Biophys Acta 1791: 646-658.
RUNE GM, WEHRENBERG U, PRANGE-KIEL J, ZHOU L, ADELMANN G, FROTSCHER M (2002) Estrogen up-regulates estrogen receptor alpha and synaptophysin in slice cultures of rat hippocampus. Neuroscience 113: 167-175.

SHIBUYA K, TAKATA N, HOJO Y, FURUKAWA A, YASUMATSU N, KIMOTO T, ENAMI T, SUZUKI K, TANABE N, ISHII H, MUKAI H, TAKAHASHI T, HATTORI TA, KAWATOS (2003) Hippocampal cytochrome P450s synthesize brain neurosteroids which are paracrine neuromodulators of synaptic signal transduction. Biochim Biophys Acta 1619: 301-316.

SKINNER DC, CARATY A (2002) Measurement and possible function of GnRH in cerebrospinal fluid in ewes. Reprod Supp/ 59: 25-39.

SPENCER JL, WATERS EM, ROMEO RD, WOOD GE, MILNER TA, MCEWEN BS (2008) Uncovering the mechanisms of estrogen effects on hippocampal function. Front Neuroendocrinol 29: 219-237.

TADA T, SHENG M (2006) Molecular mechanisms of dendritic spine morphogenesis. Curr Opin Neurobiol 16: 95-101.

VIERK R, GLASSMEIER G, ZHOU L, BRANDT N, FESTER L, DUDZINSKI D, WILKARS W, BENDER RA, LEWERENZM, GLOGER S, GRASER L, SCHWARZ J, RUNE GM (2013). Aromatase inhibition abolishes LTP generation in female but not in male mice. J Neurosci 32: 8116-8126.

WEHRENBERG U, PRANGE-KIEL J, ZHOU L, RUNE GM (2001) Steroidogenic factor-1 (SF-1) is a possible regulator of neurosteroidsynthesis in the hippocampus. Biol. Reprod. 64: 251-251.

WITCHER MR, KIROV SA, HARRIS KM (2007) Plasticity of perisynaptic astroglia during synaptogenesis in the mature rat hippocampus. Glia 55: 13-23.

WOOLLEY CS, GOULDE, FRANKFURT M, MCEWENBS (1990) Naturally-Occurring Fluctuation in Dendritic Spine Density on Adult Hippocampal Pyramidal Neurons. J. Neuroscience 10: 4035-4039.

YUSTE R, BONHOEFFER T (2001) Morphological changes in dendritic spines associated with long-term synaptic plasticity. Annu Rev Neurosci 24: 1071-1089.

YUSTE R, BONHOEFFER T (2004) Genesis of dendritic spines: insights from ultrastructural and imaging studies. Nat Rev Neurosci 5: 24-34.

ZHOU L, LEHAN N, WEHRENBERG U, DISTELDORF E, VON LOSSOW R, MARES U, JARRY H, RUNE GM (2007) Neuroprotection by estradiol: A role of aromatase against spine synapse loss after blockade of $\mathrm{GABA}(\mathrm{A})$ receptors. Exp Neurol 203: 72-81.

ZHOU L, FESTER L, VON BLITTERSDORFF B, HASSU B, NOGENS H, PRANGEKIEL J, JARRY H, WEGSCHEIDER K, RUNE GM (2010) Aromatase inhibitors induce spine synapse loss in the hippocampus of ovariectomized mice. Endocrinology 151: 1153-1160.

ZUO Y, LIN A, CHANG P, GAN WB (2005) Development of long-term dendritic spine stability in diverse regions of cerebral cortex. Neuron 46: 181-189. 


\section{Further Related Reading, published previously in the Int. J. Dev. Biol.}

The expression and alternative splicing of alpha-neurexins during Xenopus development Zhihong Zeng, Colin R. Sharpe, J. Paul Simons and Dariusz C. Górecki Int. J. Dev. Biol. (2006) 50: 39-46

P450 aromatase expression in the temperature-sensitive sexual differentiation of salamander (Hynobius retardatus) gonads

Natsuko Sakata, Yoichiro Tamori And Masami Wakahara

Int. J. Dev. Biol. (2005) 49: 417-425

Proliferation, cell death and reelin expression during development of the retina in a teleost, the common trout (Salmo trutta fario)

E Candal, R Anadon, HC Caruncho, I Rodriguez-Moldes

Int. J. Dev. Biol. (2001) 45: S69-S70

Sexual differentiation of reproductive tissue in bivalve molluscs: identification of male associated polypeptide in the mantle of Mytilus galloprovincialis Lmk A T Mikhailov, M Torrado and J Méndez

Int. J. Dev. Biol. (1995) 39: 545-548

Zagreb research collection of human brains for developmental neurobiologists and clinical neuroscientists

I Kostovic, M Judas, L Kostovic-Knezevic, G Simic, I Delalle, D Chudy, B Sajin and Z Petanjek Int. J. Dev. Biol. (1991) 35: 215-230

5 yr ISI Impact Factor $(2011)=2.959$
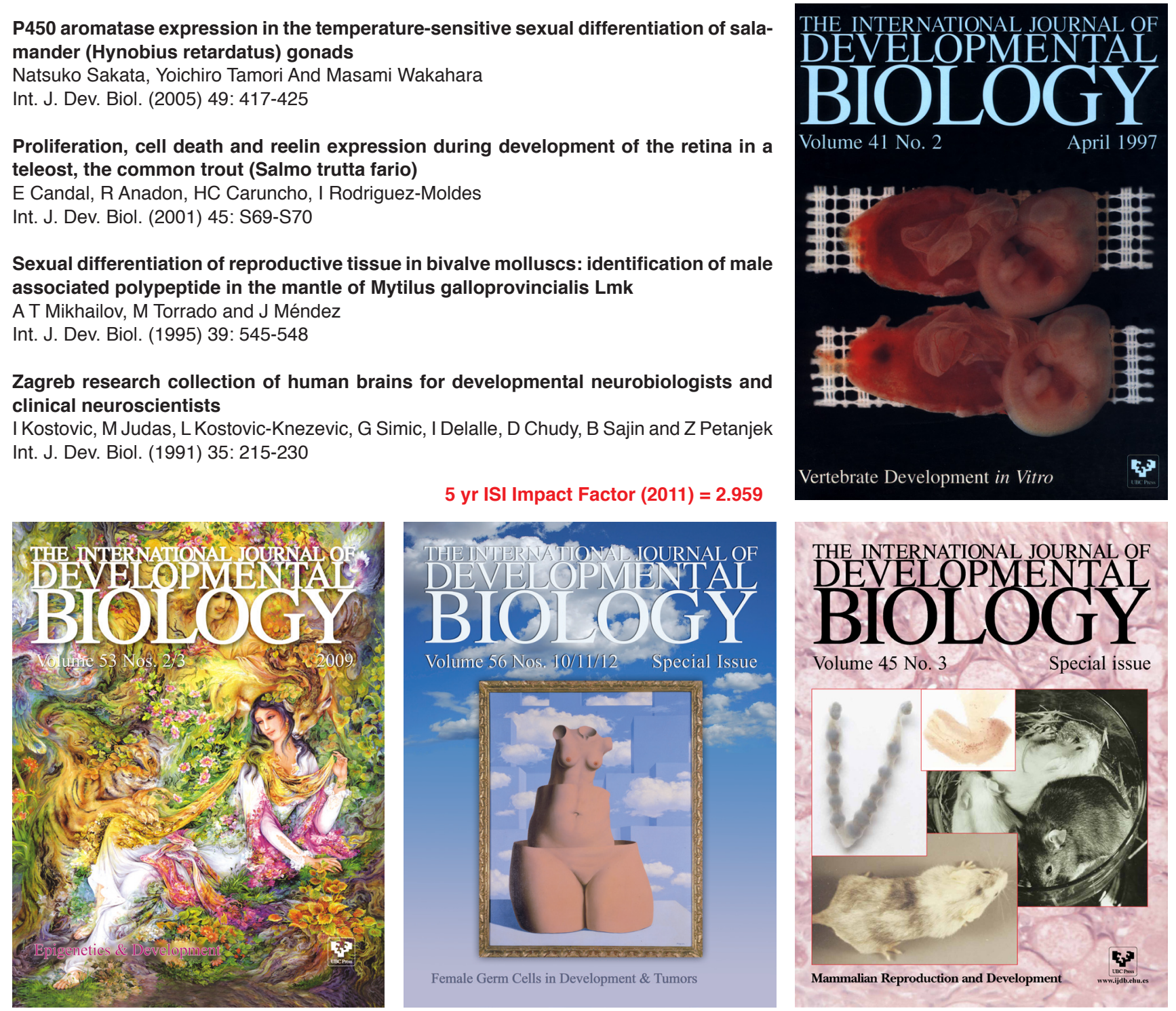